\title{
Prevalence and Age Distribution of Oral Squamous Cell Carcinoma - A Retrospective Study
}

\section{Kadambari Sriram¹, Manjari Chaudhary ${ }^{2}$, Santhosh Kumar M P³}

Section: Healthcare

Sci. Journal Impact

Factor: $6.1(2018)$

ICV: 90.90 (2018)

(c) (i) (3)

Copyright@IJCRR
'Saveetha Dental College and Hospitals, Saveetha Institute of Medical and Technical Sciences, Saveetha University, Chennai 6ooo77, India; ${ }^{2}$ Senior Lecturer, Department of Oral Medicine and Radiology, Saveetha Dental College and Hospitals, Saveetha lnstitute of Medical and Technical Sciences, Saveetha University, Chennai 600077, India; ${ }^{3}$ Reader, Department of Oral and Maxillofacial Surgery, Saveetha Dental College and Hospitals, Saveetha Institute of Medical and Technical Sciences, Saveetha University, Chennai 60oo77, India.

\section{ABSTRACT}

Background: Cancers of all regions of the oral cavity, taking into account worldwide reports is considered to be represented as the sixth most common cancer in the world. Oral cancers are believed to result due to the accumulation of genetic and epigenetic alterations. Over the past few years, there has been an increasing trend in prevalence among younger persons. This makes Oral cancer a highly relevant issue of global public health.

Objective: The aim of the present study is to evaluate the prevalence and age distribution of Oral Squamous cell carcinoma (OSCC) in patients of an institution.

Methods: The study is a hospital-based retrospective study, and included patients visiting a Dental hospital. A total of 45 patients diagnosed with OSCC were included in the study. The age, gender, anatomic site, and history of habit were evaluated and tabulated in MS Excel. The data collected was imported to IBM SPSS Version 20.0 for Chi-Square analysis and results were obtained.

Results: It was observed that OSCC was most prevalent in patients around 56 years of age. The lower arch was found to be the most frequent site of presentation (47\%). The association between gender and the occurrence of OSCC was not statistically significant $(p>0.05)$.

Conclusion: Within the limits of this study OSCC was found to be most prevalent in the 5th-6th decade of life in the lower arch Key Words: Epidemiology, Human diseases, Oral cancer, Prevalence, Risk factors, Age

\section{INTRODUCTION}

Oral cancer is a malignant neoplasm that arises on the lip or in the oral cavity. ${ }^{1}$ It is traditionally defined as a squamous cell carcinoma (OSCC), because in the dental area ${ }^{2}$, ${ }^{3}$, it has been found that $90 \%$ of cancers are histologically defined as having originated from squamous cells. ${ }^{4}$ It has been observed to have different levels of differentiation and a propensity for lymph node metastasis and involvement. ${ }^{5}$ Cancers $^{6}$ of all regions of the oral cavity ${ }^{7,8}$, taking into account worldwide reports is considered to be represented as the sixth most common cancer ${ }^{9}$ in the world. ${ }^{10,11}$ Oral cancers are believed to result due to the accumulation of genetic and epigenetic alterations. ${ }^{12-14}$

The most important risk factors ${ }^{15}$ associated with OSCC are the use of tobacco or betel quid and the regular drinking of alcoholic beverages. ${ }^{16,17}$ Apart from these, infection ${ }^{18}$ with high-risk human papillomavirus (HPV) genotypes, and $\operatorname{diet}^{19}$ low in fresh fruits ${ }^{20}$ and vegetables have also been attributed to the etiopathogenesis of OSCC. ${ }^{21,22}$

OSCC is managed by surgery, radiation, and chemotherapy in combination or in a singular fashion; but despite the various treatment modalities, the five-year survival rate is poor. This can be attributed to the fact that by the time of diagnosis, the size of the lesion is already quite large. The highest incidence ${ }^{23}$ and prevalence of OSCC is found in the Indian subcontinent due to prevalent habits of chewing tobacco and betel quid. ${ }^{24,25}$ Over the past few years, there has been an increasing trend in prevalence among younger persons. ${ }^{26,27}$ This makes Oral cancer a highly relevant issue of global public health. This paper aims to report the

\section{Corresponding Author:}

Manjari Chaudhary, Senior Lecturer, Department of Oral Medicine and Radiology, Saveetha Dental College and Hospitals, Saveetha Institute of Medical and Technical Sciences, Saveetha University, 162, PH Road, Chennai 600077, Tamil Nadu, India; Contact:+91 7044455554; Email: manjaric.sdc@saveetha.com

ISSN: 2231-2196 (Print)

Received: 16.09 .2020
ISSN: 0975-5241 (Online)

Revised: 19.10 .2020
Accepted: 14.11 .2020
Published: 26.12 .2020 
prevalence and age distribution of OSCC among patients of an institution.

\section{MATERIALS AND METHODS}

In this retrospective study, patients who were diagnosed with OSCC in a Dental Hospital from June 2019 to March 2020 were included. A consecutive sampling method was used for the study. The study was commenced after approval from the scientific review board, and the ethical clearance was obtained from the ethical committee of the University with the following ethical approval number-SDC/SIHEC/2020/ DIASDATA/0619-0320.

Patients of all age groups, both males and females were included in the study. All cases of OSCC were taken into consideration and their digital case records including preoperative and intra-operative as well as the history of adverse habits with digital photographs were retrieved. Only those case records which were approved by the specialists were included. Patients with potentially malignant lesions or carcinoma of non-squamous origin, with incomplete/ censored records, were excluded from the study. 45 samples that satisfied the criteria were included in the study. Variables such as age, gender, history of habit were extracted.

\section{Statistical Analysis}

The results obtained were tabulated and exported to IBM SPSS Version 20.0 for Statistical analysis. Descriptive Data analysis was done using percentages for Nominal and Qualitative data. The Age, Gender, and History of habit were considered as the independent variables while the anatomic site was considered as the dependent variable. Chi-square Test was used to evaluate the association between Age, Gender, and the occurrence of OSCC. The $\mathrm{p}$-value less than 0.05 were considered as statistically significant.

\section{RESULTS AND DISCUSSION}

The present study included a total of 45 patients, of which 35 were males $(77 \%)$ and 10 were females $(23 \%)$ with an age range of 30-70 years. The mean age of the patients diagnosed with OSCC was 55 years of age (Figure 1). A majority of $66 \%$ of the patients did not have a history of any habit (Figure 4).

On analysis, the greatest prevalence of OSCC was found between the 5th and 6th decade of life (37\%). This was closely followed by prevalence in the 4 th to 5 th decade of life $(25 \%)$ (Table 1, Figure 1). The highest frequency of presentation of OSCC was found in the lower arch (47\%), followed by both arches (40\%) (Figure 2). On statistical analysis using Chi-square Test. However, no significant association was found between age and anatomical site, p $>0.05$ (Figure 2). Considering gender a greater prevalence was seen in males than in females (Table 2, Figure $3)$. The association with gender and the anatomic site was not found to be statistically significant, $\mathrm{p}>0.05$ on analysis using Chi-square Test (Figure 3).

OSCC distribution is highest between the 5th and 6th decade of life in the present study. Greater prevalence of OSCC was found in males than in females in our study however no significant association was found between occurrence and gender. The majority of the cases of OSCC had a presentation in the lower arch followed by a presentation in both arches in our study.

Oral cancer was found to be most prevalent from the fifth decade of life to the seventh decade of life in the previous studies. ${ }^{28}$ This is in accordance with our study where the highest distribution was between the fifth and sixth decade of life. In the present study, a significant number of cases were also found between the 4 th and 5 th decade which seems to be a slowly increasing trend in recent years. This is consistent with findings from previous studies that suggest $<3 \%$ increase in the incidence of OSCC among patients less than 50 years of age in recent times. ${ }^{29-31}$

The lower arch was found to be the most affected region in the present study closely followed by the clinical presentation in both arches. This is in consensus with a study by Bagan et al., where the majority $(20-40 \%)$ of the cases clinical presentation in the lower arch, tongue ${ }^{32}$, and floor of the mouth. ${ }^{33}$ This can be attributed to the habit of placement of the betel quid in the lower arch.

Greater prevalence of OSCC was found when compared in males than in females in the present study. This is similar to previous studies which found 1.5- 2 times greater prevalence in males than in females. ${ }^{34}$ However, the association between occurrence and gender was not statistically significant in our study. This can be explained by the fact that over the years women have been equally exposed to oral carcinogens like tobacco and alcohol. ${ }^{35}$

The results of the present study indicate that middle-aged persons are most susceptible to OSCC with clinical presentation in the lower arch being most common. The limitations of the study include that it is a single centre study with limited sample size. Further scope of the study includes conducting a multicentre study with a larger study population and consideration of risk factors. 


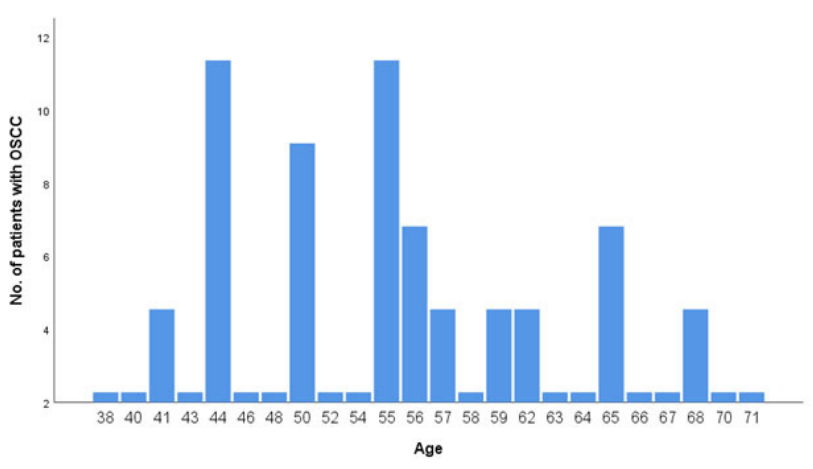

Figure 1: Bar chart depicting the age distribution of patients with OSCC. X-axis denotes the Age of patients and Y-axis denotes the number of patients. The ages range from $35-75$ years. The mean age of the patients with OSCC is around 55 years.

Table 1: Table depicting the Age distribution by anatomic site: Highest prevalence is seen in the lower arch (LA). Greater presentation in both arches (BA) seen below 55 years of age. The least presentation is seen in the upper arch (UA).

\begin{tabular}{llcccc}
\multicolumn{5}{c}{ Age distribution by Anatomic site of OSCC } \\
\multicolumn{5}{c}{ Anatomical site } \\
BA & LA & UA & Total \\
Age Group & $\begin{array}{l}45 \text { and } \\
\text { below }\end{array}$ & 7 & 3 & 0 & 10 \\
& $46-55$ & 7 & 4 & 2 & 13 \\
& $56-65$ & 4 & 9 & 2 & 15 \\
& 66 and & 0 & 5 & 1 & 6 \\
above & & & & \\
Total & & 18 & 21 & 5 & 45 \\
\hline
\end{tabular}

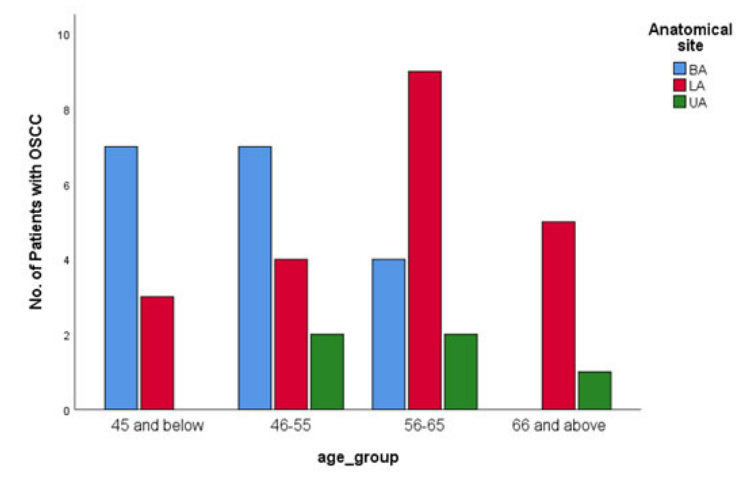

Figure 2: Bar graph depicting the association between age and anatomic site of oral squamous cell carcinoma (OSCC). $\mathrm{X}$-axis denotes the age group and $\mathrm{Y}$-axis denotes the number of patients. Pearson Chi-Square test, $\mathrm{df}=6, \mathrm{P}$-value $=0.09$, $P>0.05$. The greatest prevalence is seen in the lower arch (Red). A higher prevalence of OSCC is observed between the 5th-6th decades. Prevalence in both arches (Blue) is seen in patients below 45 years of age. The least presentation is seen in the upper arch (Green). The association of Age with an Anatomic site is not statistically significant.
Table 2: Table depicting the Gender distribution by anatomic site: Highest prevalence is seen in males than in females. The lower arch (LA) appears to be the most affected site.

\begin{tabular}{|c|c|c|c|c|c|}
\hline \multicolumn{6}{|c|}{ Gender distribution by Anatomic site of OSCC } \\
\hline & & \multicolumn{3}{|c|}{ Anatomic Site } & \multirow{2}{*}{ Total } \\
\hline & & BA & LA & UA & \\
\hline \multirow[t]{2}{*}{ Gender } & Female & 4 & 4 & 1 & 9 \\
\hline & Male & 14 & 17 & 4 & 35 \\
\hline Total & & 18 & 21 & 5 & 45 \\
\hline
\end{tabular}

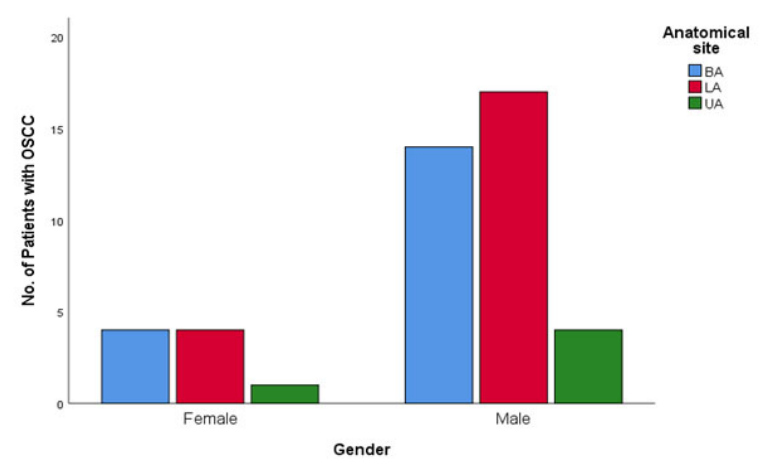

Figure 3: Bar graph depicting the Association between Gender and anatomic site of OSCC. X-axis denotes Gender (Female / Male) and Y-axis denotes the number of patients. The prevalence of OSCC was higher among the male population (35). Among the male population, the prevalence of OSCC was higher in the lower arch (red) as well as in both arches (blue). Among the female population, an equal number of patients reported with OSCC in the lower arch and both the arches. Pearson Chi-Square test shows, $\mathrm{df}=2, \mathrm{P}$-value $=0.97, \mathrm{P}>0.05$. However, statistical analysis of the association of Gender with an anatomic site is not statistically significant.

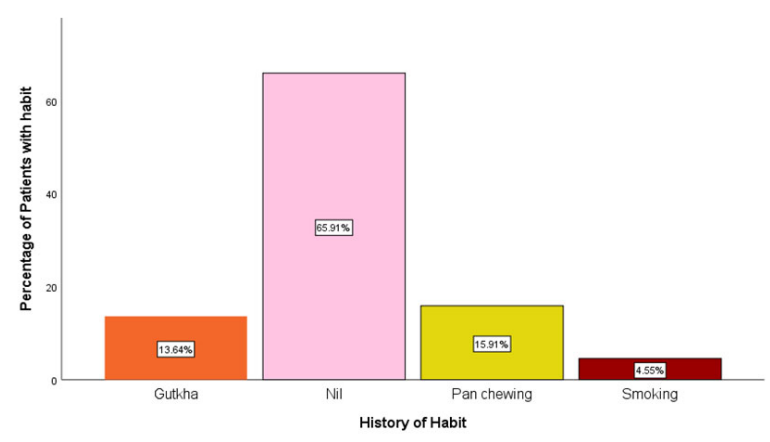

Figure 4: Bar graph depicting the prevalence of the adverse habits among patients with OSCC. X-axis denotes the adverse habits (Gutkha, betel quid chewing, smoking, and no habit) and $\mathrm{Y}$-axis denotes the percentage of patients. A majority of around $65.9 \%$ of the study population had no adverse habits (Pink) followed by $15.9 \%$ having betel quid chewing habit (Yellow), $13.64 \%$ with gutkha habit (Orange), and $4.5 \%$ with the smoking habit (Brown). 


\section{CONCLUSION}

Within the limits of the present study, we can conclude that OSCC is most prevalent in the 5th-6th decade of life, more in males with the presentation in the lower arch. The management of oral cancer mainly depends on prevention and early diagnosis. Educational camps and campaigns are needed on the local, state, and national level in order to educate the public about the risk factors and early signs/symptoms associated with oral cancer. The general population also need to be encouraged to seek regular oral examinations by dentists.

\section{ACKNOWLEDGEMENTS}

We would like to thank the administration of Saveetha University, Chennai for granting us the clearance to conduct this study.

\section{Authors Contribution}

Kadambari Sriram contributed to the acquisition of data, analysis, literature collection, and in drafting the article and revising it critically for important intellectual content.

Dr. Manjari Chaudhary contributed to conception, study design, interpretation of data, formatting, manuscript preparation, supervision, and guidance.

Dr. Santhosh Kumar contributed to the editing, supervision, and final approval of the submitted version of the manuscript.

\section{Conflict of Interest}

The authors declare that there is no conflict of interest

Financial Support: None

\section{REFERENCES}

1. Lingen MW, Kalmar JR, Karrison T, Speight PM. Critical evaluation of diagnostic aids for the detection of oral cancer. Oral Oncol 2008;44(1):10-22.

2. Subha M, Arvind M. Role of Magnetic Resonance Imaging in Evaluation of Trigeminal Neuralgia with its Anatomical Correlation. Biomed Pharmacol J 2019;12:289-96.

3. Choudhury P, Panigrahi RG, Maragathavalli, Panigrahi A, Patra PC. Vanishing roots: first case report of idiopathic multiple cervico-apical external root resorption. J Clin Diagn Res 2015;9(3):ZD17-9.

4. Barnes L. World Health Organisation IA for R on C. Pathology and Genetics of Head and Neck Tumours 2005.

5. Rivera C. Essentials of oral cancer. Int J Clin Exp Pathol 2015;8(9):11884-94.

6. Muthukrishnan A, Kumar LB. Actinic cheilosis: early intervention prevents malignant transformation. BMJ Case Reports 2017:bcr2016218654.

7. Rohini S, Kumar VJ. Incidence of dental caries and pericoronitis associated with impacted mandibular third molar-A radiographic study. Res J Pharma Tech 2017;10(4):1081-4.
8. Dharman S, Muthukrishnan A. Oral mucous membrane pemphigoid - Two case reports with varied clinical presentation. J Indian Soc Periodontol 2016;20(6):630-4.

9. Misra SR, Shankar YU, Rastogi V, Maragathavalli G. Metastatic hepatocellular carcinoma in the maxilla and mandible, an extremely rare presentation. Contemp Clin Dent 2015;6(Suppl 1):S117-21.

10. Warnakulasuriya S. Global epidemiology of oral and oropharyngeal cancer. Oral Oncol 2009;45(4-5):309-16.

11. Maheswari TNU, Venugopal A, Sureshbabu NM, Ramani P. Salivary micro RNA as a potential biomarker in oral potentially malignant disorders: A systematic review. Tzu Chi Med J 2018;30(2):55-60.

12. Little MP. Cancer models, genomic instability and somatic cellular Darwinian evolution. Biol Direct 2010;5:19.

13. González-Ramírez I, Irigoyen-Camacho ME, Ramírez-Amador V, Lizano-Soberón M, Carrillo-García A, García-Carrancá A, et al. Association between age and high-risk human papilloma virus in Mexican oral cancer patients. Oral Dis 2013;19(8):796-804.

14. Venugopal A, Uma Maheswari TN. Expression of matrix metalloproteinase-9 in oral potentially malignant disorders: A systematic review. J Oral Maxillofac Pathol 2016;20(3):474-9.

15. Subashri A, Maheshwari TN. Knowledge and attitude of oral hygiene practice among dental students. J Pharm Res 2016.

16. Hashibe M, Brennan $\mathrm{P}$, Chuang S, Boccia S. Interaction between tobacco and alcohol use and the risk of head and neck cancer: pooled analysis in the International Head and Neck Cancer Epidemiology. Cancer Epidemiol Biomarkers Prev. 2009 Feb; 18(2): 541-550.

17. Anantharaman D, Marron M, Lagiou P, Samoli E, Ahrens $\mathrm{W}$, Pohlabeln $\mathrm{H}$, et al. Population attributable risk of tobacco and alcohol for upper aerodigestive tract cancer. Oral Oncol 2011;47(8):725-31.

18. Muthukrishnan A, Kumar LB, Ramalingam G. Medication-related osteonecrosis of the jaw: a dentist's nightmare. BMJ Case Reports 2016:bcr2016214626.

19. Chaitanya NC, Muthukrishnan A, Babu DBG, Kumari CS, Lakshmi MA, Palat G, et al. Role of Vitamin E and Vitamin A in Oral Mucositis Induced by Cancer Chemo/Radiotherapy- A Meta-analysis. J Clin Diagn Res 2017;11(5):ZE06-9.

20. Chaitanya NC, Muthukrishnan A, Krishnaprasad CMS, Sanjuprasanna G, Pillay P, Mounika B. An Insight and Update on the Analgesic Properties of Vitamin C. J Pharm Bioallied Sci 2018;10(3):119-25.

21. Petti S. Lifestyle risk factors for oral cancer. Oral Oncol 2009;45(4-5):340-50.

22. Notani PN, Sanghvi LD. Role of diet in the cancers of the oral cavity. Indian J Cancer 1976;13(2):156-60.

23. Steele JC, Clark HJ, Hong CHL, Jurge S, Muthukrishnan A, Kerr AR, et al. World Workshop on Oral Medicine VI: an international validation study of clinical competencies for advanced training in oral medicine. Oral Surg Med Pathol Radiol 2015 ;120(2):143-51.

24. Attar E, Dey S, Hablas A, Seifeldin IA, Ramadan M, Rozek LS, et al. Head and neck cancer in a developing country: A population-based perspective across 8 years. Oral Oncology 2010;46:591-6.

25. Muthukrishnan A, Warnakulasuriya S. Oral health consequences of smokeless tobacco use. Indian J Med Res 2018;148(1): 35-40.

26. Rapidis AD, Gullane P, Langdon JD, Lefebvre JL, Scully C, Shah JP. Major advances in the knowledge and understanding of the epidemiology, aetiopathogenesis, diagnosis, management and prognosis of oral cancer. Oral Oncol 2009;45(4-5):299-300. 
27. Patil SR, Maragathavalli G, Araki K, Al-Zoubi IA, Sghaireen MG, Gudipaneni RK, et al. Three-Rooted Mandibular First Molars in a Saudi Arabian Population: A CBCT Study. Pesqui Bras Odontopediatria Clin Integr 2018;18(1):4133.

28. Iype EM, Pandey M, Mathew A, Thomas G. Squamous cell carcinoma of the tongue among young Indian adults. (New York, NY) 2001

29. Llewellyn CD, Linklater K, Bell J, Johnson NW, Warnakulasuriya S. An analysis of risk factors for oral cancer in young people: a case-control study. Oral Oncol 2004;40(3):304-13.

30. Falaki F, Dalirsani Z, Pakfetrat A, Falaki A, Saghravanian N, Nosratzehi T, et al. Clinical and histopathological analysis of oral squamous cell carcinoma of young patients in Mashhad, Iran: a retrospective study and review of literature. Med Oral Pathol Cir Bucal 2011;16(4):e473-7.
31. Kaminagakura E, Villa LL, Andreoli MA, Sobrinho JS, Vartanian JG, Soares FA, et al. High-risk human papillomavirus in oral squamous cell carcinoma of young patients. Int $\mathrm{J}$ Cancer 2012;130(8):1726-32.

32. Kayal L, Jayachandran S, Bhaskar YH. Squamous Cell Carcinoma of Tongue-A Case Report and Review of Literature. Int J Curr Res Rev 2016;8(9):64.

33. Bagan J, Sarrion G, Jimenez Y. Oral cancer: clinical features. Oral Oncol 2010;46(6):414-7.

34. Feller L, Lemmer J. Oral squamous cell carcinoma: epidemiology, clinical presentation and treatment. J Cancer Therap 2012;3(4).

35. Neville BW, Day TA. Oral cancer and precancerous lesions. CA Cancer J Clin 2002;52(4):195-215. 